\section{BRAZIULIAN JOURNAL \\ OF MEDICAL AND BIOLOGICAL RESF.ARCH}

www.bjournal.com.br
ISSN 0100-879X

Volume 42 (12) 1119-1247 December 2009

BIOMEDICAL SCIENCES

AND

CLINICAL INVESTIGATION

Braz J Med Biol Res, December 2009, Volume 42(12) 1128-1137

Expression of E-cadherin, Snail and Hakai in epithelial cells isolated from the primary tumor and from peritumoral tissue of invasive ductal breast carcinomas

F.B.A. Makdissi, L.V.S.T. Machado, A.G.C. Oliveira, T.T. Benvenuti, M.L.H. Katayama, M.M. Brentani, C.A.B.T. Osório, M. Mourão Netto, E.C. Lyra, F. Carvalho, J.C.S. Góes and M.A.A.K. Folgueira

The Brazilian Journal of Medical and Biological Research is partially financed by
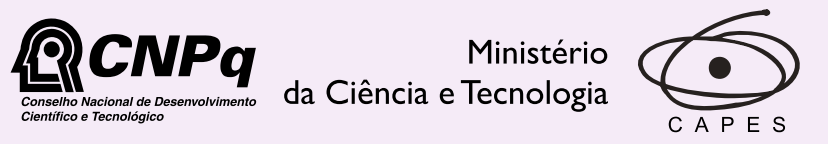

Ministério da Educação

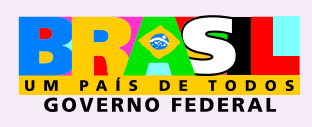

Institutional Sponsors 


\title{
Expression of E-cadherin, Snail and Hakai in epithelial cells isolated from the primary tumor and from peritumoral tissue of invasive ductal breast carcinomas
}

\author{
F.B.A. Makdissi ${ }^{1,2 *}$, L.V.S.T. Machado1,3*, A.G.C. Oliveira ${ }^{1,2 *}$, T.T. Benvenuti ${ }^{1}$, \\ M.L.H. Katayama1 ${ }^{1}$, M.M. Brentani ${ }^{1}$, C.A.B.T. Osório ${ }^{2}$, M. Mourão Netto ${ }^{2}$, \\ E.C. Lyra ${ }^{1,4}$, F. Carvalho ${ }^{2}$, J.C.S. Góes ${ }^{4}$ and M.A.A.K. Folgueira ${ }^{1}$ \\ ${ }^{1}$ Disciplina de Oncologia, Departamento de Radiologia, Faculdade de Medicina, \\ Universidade de São Paulo, São Paulo, SP, Brasil \\ ${ }^{2}$ Hospital do Câncer A.C. Camargo, São Paulo, SP, Brasil \\ ${ }^{3}$ Programa de Pós-Graduação Interunidades em Biotecnologia, \\ Instituto de Ciências Biomédicas, Universidade de São Paulo, São Paulo, SP, Brasil \\ ${ }^{4}$ Instituto Brasileiro de Controle do Câncer, São Paulo, SP, Brasil
}

\begin{abstract}
Epithelial intercellular cohesion, mainly mediated by E-cadherin (CDH1) expression and function, may be deregulated during cancer cell invasion of adjacent tissues and lymphatic and vascular channels. CDH1 expression is down-modulated in invasive lobular breast carcinomas but its regulation in invasive ductal carcinomas (IDC) is less clear. CDH1 expression is repressed by transcription factors such as Snail (SNAI1) and its product is degraded after Hakai ubiquitination. We compared CDH1, SNAI1 and HAKAI mRNA expression in IDC and paired adjacent normal breast tissue and evaluated its relation with node metastasis and circulating tumor cells. Matched tumor/peritumoral and blood samples were collected from 30 patients with early IDC. Epithelial cells from each compartment (tumor/peritumoral) were recovered by an immunomagnetic method and gene expression was determined by real-time RT-PCR. There were no differences in CDH1, SNAI1 and HAKAI mRNA expression between tumor and corresponding peritumoral samples and no differential tumoral gene expression according to nodal involvement. Another 30 patients with a long-term follow-up (at least 5 years) and a differential prognosis (good or poor, as defined by breast cancer death) had E-cadherin and Snail protein detected by immunohistochemistry in tumor samples. In this group, E-cadherin-positive expression, but not Snail, may be associated with a better prognosis. This is the first report simultaneously analyzing CDH1, SNAI1 and HAKAI mRNA expression in matched tumor and peritumoral samples from patients with IDC. However, no clear pattern of their expression could distinguish the invasive tumor compartment from its adjacent normal tissue.
\end{abstract}

Key words: Breast cancer; E-cadherin; Snail; Hakai

\section{Introduction}

To invade, breast cancer cells reduce their intercellular cohesion, lose polarity, enhance their motility and proteolytic activity, and acquire mesenchymal cell characteristics, undergoing a dramatic remodeling of the cytoskeleton in a process similar to the epithelial-mesenchymal transition (EMT) that takes place during embryogenesis $(1,2)$. Invasive carcinomas may then spread through lymphatic or vascular channels and metastasize to regional lymph nodes and distant sites.

Functional loss of E-cadherin ( $\mathrm{CDH} 1)$ in an epithelial cell has been considered a hallmark of EMT. CDH1 expression may be repressed by transcription factors such as Snail (SNAI1), ZEB1 and Slug (2-4). Snail belongs to a family of zinc-finger-containing transcriptional repressors implicated in the regulation of the EMT phenomenon (5) and, accordingly, Snail transfection into epithelial cells leads to a more

Correspondence: M.A.A.K. Folgueira, Disciplina de Oncologia, Departamento de Radiologia, FM-USP, Av. Dr. Arnaldo, 455, Sala 4112, 01246-903 São Paulo, SP, Brasil. Fax: +55-11-3082-6580. E-mail: makoike@lim24.fm.usp.br

*These authors contributed equally to this study.

Received July 3, 2009. Accepted October 20, 2009. Available online November 9, 2009. Published December 4, 2009. 
fibroblastic phenotype (3).

E-cadherin expression may also be controlled by its internalization and subsequent degradation by the proteosome system, mainly mediated by Hakai, an E3 ubiquitinligase that interacts with E-cadherin, inducing ubiquitination of the complex. Expression of Hakai in epithelial cells disrupts cell-cell contacts and enhances endocytosis of E-cadherin and cell motility (6).

Although in invasive lobular carcinoma of the breast there is almost a universal loss of E-cadherin expression, in non-lobular invasive carcinomas, its absence is not so

Table 1. Characteristics of breast carcinoma patients who had fresh tissue collected during surgery for epithelial cell selection.

\begin{tabular}{rcccccccc}
\hline ID & Age & pT & pN & CS & HG & ER & PR & ErbB2 \\
\hline 1 & 49 & 1 & 1 & II & 1 & $(+)$ & $(+)$ & $(+)$ \\
2 & 48 & 2 & 0 & II & 2 & $(-)$ & $(-)$ & $(-)$ \\
3 & 78 & 2 & 0 & II & 2 & $(+)$ & $(+)$ & $(+)$ \\
4 & 58 & 1 & 2 & III & 2 & $(+)$ & $(+)$ & $(-)$ \\
5 & 85 & 2 & 0 & II & 2 & $(+)$ & $(+)$ & $(-)$ \\
6 & 53 & 2 & 0 & II & 2 & $(+)$ & $(+)$ & $(-)$ \\
7 & 43 & 1 & 0 & I & 2 & $(+)$ & $(+)$ & $(-)$ \\
8 & 73 & 2 & 2 & III & 2 & $(+)$ & $(+)$ & $(-)$ \\
9 & 56 & 2 & 3 & III & 3 & $(+)$ & $(+)$ & $(+)$ \\
10 & 52 & 1 & 0 & I & 3 & $(+)$ & $(+)$ & $(+)$ \\
11 & 85 & 3 & 1 & III & 2 & $(-)$ & $(-)$ & $(-)$ \\
12 & 54 & 2 & 3 & III & 2 & $(-)$ & $(-)$ & $(-)$ \\
13 & 47 & 1 & 1 & II & 2 & $(-)$ & $(+)$ & $(-)$ \\
14 & 76 & 2 & 1 & II & 2 & $(+)$ & $(+)$ & $(-)$ \\
15 & 58 & 1 & 1 & II & 1 & $(+)$ & $(-)$ & $(+)$ \\
16 & 46 & 1 & 0 & I & 1 & $(+)$ & $(+)$ & $(+)$ \\
17 & 40 & 2 & 1 & II & 1 & $(+)$ & $(+)$ & ND \\
18 & 53 & 1 & 2 & III & 1 & $(+)$ & $(+)$ & $(+)$ \\
19 & 51 & 2 & 1 & II & 3 & $(+)$ & $(+)$ & $(-)$ \\
20 & 47 & 1 & 0 & I & 2 & $(+)$ & $(-)$ & $(-)$ \\
21 & 50 & 1 & 1 & II & 3 & $(+)$ & $(-)$ & $(-)$ \\
22 & 49 & 3 & 3 & III & 3 & $(+)$ & $(+)$ & $(-)$ \\
23 & 55 & 2 & 0 & II & 2 & $(+)$ & $(+)$ & $(-)$ \\
24 & 43 & 3 & 3 & III & 3 & $(+)$ & $(+)$ & $(-)$ \\
25 & 62 & 1 & 0 & I & 2 & $(+)$ & $(+)$ & $(+)$ \\
26 & 58 & 1 & 0 & I & 2 & $(+)$ & $(-)$ & $(-)$ \\
27 & 53 & 1 & 0 & I & ND & $(+)$ & $(+)$ & $(-)$ \\
28 & 70 & 1 & 0 & I & 2 & $(+)$ & $(+)$ & $(-)$ \\
29 & 42 & 1 & 0 & I & 3 & $(+)$ & $(+)$ & $(-)$ \\
30 & 91 & 1 & 0 & I & 3 & $(+)$ & $(+)$ & $(-)$ \\
\hline & & & & & & & & \\
& 1 & & & $(+)$
\end{tabular}

$\mathrm{ID}=$ patient identification; Age $=$ in years; $\mathrm{pT}=$ pathological tumor size; $\mathrm{pN}$ = pathological lymph node involvement; $\mathrm{CS}=$ clinical stage TNM (AJCC Cancer Staging Manual, 6th edition, 2003); $\mathrm{HG}=$ histologic grade; $\mathrm{ER}=$ estrogen receptor; $\mathrm{PR}=$ progesterone receptor; $(+)$ positive and $(-)$ negative immunoexpression; ErbB2(+) only if +++ . ND $=$ not determined. Blood samples were also collected from patients 1-13 to detect circulating tumor cells. common, but may play a role in progression, development of distant metastases and recurrence (7-9).

Our aim was to determine whether there are differences in E-cadherin, Snail and Hakai transcript expression (related to the EMT) between paired tumor and adjacent normal tissue from patients with invasive ductal breast carcinoma. Additionally, we also determined whether the tumoral expression of these genes could be associated with cell shedding and consequent regional and distant metastases.

\section{Patients and Methods}

Thirty patients were prospectively recruited at two reference cancer centers in São Paulo, Brazil: Hospital do Câncer A.C. Camargo and Instituto Brasileiro de Controle do Câncer, from December 2003 to November 2005. The study was approved by the Institutional Ethics Committee and written informed consent was signed by all participants. Fresh tumor and adjacent normal tissue samples were collected from these patients during tumor resection for epithelial cell recovery and gene expression analysis.

The median age of the patients was 53 years (Table 1), $76.7 \%$ of the women were postmenopausal, $53.3 \%$ presented T1 lesions, and $50.0 \%$ presented lymph node involvement. Thirty-five percent of the patients presented pathological stage III disease and none of them had distant metastases, as evaluated by abdominal ultrasound, chest radiographs (posteroanterior and lateral) and a bone scan. Invasive ductal carcinoma was diagnosed in all patients, being histologic grade 3 in $27.6 \%$ of cases. Immunohistochemical expression of estrogen receptor, progesterone receptor and ERBB2 was detected in 86.7, 76.7 and $24.1 \%$ of the tumors, respectively. None of the patients had been previously treated for a breast carcinoma.

Another group of 30 patients with invasive ductal carcinoma diagnosed between 1994 and 1995 at Hospital do Câncer A.C. Camargo with a long-term follow-up (at least 5 years, median 93.3 months) had paraffin-embedded tumor samples available for immunohistochemistry reactions. Median age was 48.5 years (Table 2) and patients had at least 13 lymph nodes dissected during the surgical procedure. Twenty-one of these patients were assigned to a good prognosis group since they did not present lymph node involvement at diagnosis and had not developed regional or distant metastases during the follow-up period. Nine patients were assigned to a poor prognosis group since they presented histopathological involvement of axillary nodes upon diagnosis. In addition, 1 of them presented a distant metastasis at diagnosis (clinical stage IV disease) and the other 8 developed distant metastases. Breast cancer death followed after $18.1-80$ months. Seventy-one and $22 \%$ of the patients were premenopausal in the good and poor prognosis group, respectively $(P=0.02$, Fisher exact test). Estrogen receptor immunoexpression was positive in 12/19 
and $2 / 7$ patients of the good and poor prognosis groups, respectively $(P=0.190$, Fisher exact test).

\section{Sample harvesting and processing}

Fresh tumor samples and corresponding peritumoral tissue situated at least $1 \mathrm{~cm}$ from the visual border of the tumor were collected during surgery. Tumor and peritumoral samples were individually subjected to mechanical disaggregation using scalpel blades and to enzymatic disaggregation using $2 \mathrm{mg} / \mathrm{mL}$ type 1 collagenase and 2 $\mathrm{mg} / \mathrm{mL}$ hyaluronidase (Sigma-Aldrich, UK) for $18 \mathrm{~h}$ at $37^{\circ} \mathrm{C}$, with intermittent shaking. After filtering, the resulting cell suspension was submitted to epithelial cell positive selection with Dynabead (CELLection Epithelial Enrich, Dynal Biotech, USA).

Tumor cells released from the primary site into vascular channels may be detected in the mononuclear compartment of blood samples. To avoid contamination with cutaneous epithelial cells, the first $3 \mathrm{~mL}$ blood was discarded after venipuncture and $10 \mathrm{~mL}$ blood was collected with a second syringe. Mononuclear cells (MNCs) were recovered after a density gradient using Ficoll-Paque PLUS (Amersham Biosciences, GE HealthCare Bio-Sciences Corp., USA).

\section{Immunomagnetic epithelial cell separation}

Dynabeads, used for epithelial cell selection, are superparamagnetic polystyrene beads coated with anti-human Ber-EP4 antibody, directed against a 34- and 49-kD glycopeptide expressed by human epithelial cells (10).

Each tumor (or peritumoral) cell suspension was mixed with $125 \mu \mathrm{L}$ Dynabeads for $3 \mathrm{~h}$ at $4^{\circ} \mathrm{C}$ with gentle rotation. The rosetted cells were isolated by placing the tube in a Dynal magnetic particle concentrator (Dynal Biotech) for 6 min at $4^{\circ} \mathrm{C}$. The same procedure was carried out to recover epithelial cells from blood mononuclear cells, which were incubated with $25 \mu \mathrm{L}$ Dynabeads.

To evaluate the efficacy of cell enrichment using this procedure, MCF-7 breast cancer cells were co-cultivated with fibroblasts (F) for $48 \mathrm{~h}$ (1 F:10 MCF-7) and, after trypsinization, the cell suspension was incubated with Dynabeads as described. Cytospins revealed that all recovered cells were cytokeratin-positive (data not shown).

\section{RNA extraction, reverse transcription and real-time RT-PCR}

Total RNA was isolated using the Trizol reagent (Invitrogen Life Technologies, USA) according to the manufacturer protocol. One microgram RNA was incubated for 15 min at

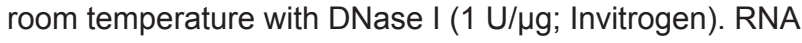
quality was confirmed by absorbance measurement ratio $260 / 280$, which was $>1.7$, and by observation of $18 \mathrm{~S} / 28 \mathrm{~S}$ rRNA by agarose gel ( $1 \%$ ) electrophoresis under denaturing conditions and visualization with ethidium bromide (ratio >1.0). The reverse transcription reaction was carried out using hexamer random primers (Amersham Biosciences),
Table 2. Characteristics of breast carcinoma patients with a longterm follow-up (at least 5 years) who had paraffin-embedded tumor samples available for analysis.

\begin{tabular}{|c|c|c|c|c|c|c|}
\hline ID & PG & Age & $\mathrm{pT}$ & $\mathrm{pN}$ & CS & ER \\
\hline 1 & $G$ & 45 & 2 & 0 & II & $(-)$ \\
\hline 2 & $G$ & 36 & 2 & 0 & II & $(-)$ \\
\hline 3 & $\mathrm{G}$ & 41 & 1 & 0 & I & $(-)$ \\
\hline 4 & $G$ & 64 & 2 & 0 & II & $(+)$ \\
\hline 5 & $G$ & 42 & 2 & 0 & II & $(-)$ \\
\hline 6 & $\mathrm{G}$ & 44 & 1 & 0 & I & ND \\
\hline 7 & $\mathrm{G}$ & 43 & 1 & 0 & I & $(-)$ \\
\hline 8 & $G$ & 70 & 1 & 0 & I & $(+)$ \\
\hline 9 & $G$ & 56 & 1 & 0 & I & $(+)$ \\
\hline 10 & $\mathrm{G}$ & 51 & 2 & 0 & II & $(+)$ \\
\hline 11 & $\mathrm{G}$ & 41 & 2 & 0 & II & $(+)$ \\
\hline 12 & $\mathrm{G}$ & 36 & 1 & 0 & I & $(+)$ \\
\hline 13 & $\mathrm{G}$ & 56 & 1 & 0 & I & $(+)$ \\
\hline 14 & G & 43 & 2 & 0 & II & $(+)$ \\
\hline 15 & $\mathrm{G}$ & 46 & 2 & 0 & II & $(+)$ \\
\hline 16 & $\mathrm{G}$ & 48 & 2 & 0 & II & $(+)$ \\
\hline 17 & $G$ & 55 & 1 & 0 & I & $(+)$ \\
\hline 18 & $G$ & 72 & 2 & 0 & II & $(-)$ \\
\hline 19 & $\mathrm{G}$ & 46 & $x$ & 0 & ND & $(+)$ \\
\hline 20 & $\mathrm{G}$ & 39 & 1 & 0 & I & ND \\
\hline 21 & G & 41 & 2 & 0 & II & $(-)$ \\
\hline 22 & $P$ & 58 & 3 & 3 & III & $(-)$ \\
\hline 23 & $P$ & 77 & 3 & 2 & IV & ND \\
\hline 24 & $P$ & 75 & 4 & 2 & III & ND \\
\hline 25 & $P$ & 49 & 2 & 1 & II & $(-)$ \\
\hline 26 & $P$ & 63 & 2 & 3 & III & $(+)$ \\
\hline 27 & $P$ & 73 & 4 & 1 & III & $(+)$ \\
\hline 28 & $P$ & 61 & 1 & 2 & III & $(-)$ \\
\hline 29 & $P$ & 39 & 2 & 2 & III & $(-)$ \\
\hline 30 & $P$ & 61 & 4 & 3 & III & $(-)$ \\
\hline
\end{tabular}

$I D$ = patient identification; $P G=$ prognostic group: $G$ (good, no lymph node involvement at diagnosis and no regional or distant metastasis during follow-up), P (poor, positive node involvement at diagnosis and distant metastasis at diagnosis (patient 23) or during follow-up, followed by breast cancer death); Age = in years; $\mathrm{pT}$ = pathological tumor size; $\mathrm{pN}=$ pathological lymph node involvement; CS = clinical stage TNM (AJCC Cancer Staging Manual, 6th edition, 2003); ER = estrogen receptor; ND = not determined.

dNTPs and Superscript ${ }^{\mathrm{TM}}$ (Invitrogen Life Technologies).

PCR primer sets (Table 3 ) were designed based on full length gene sequences in separated exons, in the coding region closer to the 3' end of the gene using the software (http://frodo.wi.mit.edu/cgi-bin/primer3/primer3_www.cgi). BLAST analysis of the primers was carried out to confirm uniqueness at www.ncbi.nlm.nih.gov/blast.

Amplification reactions were carried out using $2 \mu \mathrm{L}$ cDNA diluted 1:10, platinum Taq polymerase (Invitrogen); 
and SYBR ${ }^{\circledR}$ Green I (Sigma-Aldrich), using a LightCycler ${ }^{\mathrm{TM}}$ (Roche Diagnostics, Germany) or a Rotor-gene system (Corbett Research, Australia). Conditions consisted of $95^{\circ} \mathrm{C}$ for $2 \mathrm{~min}$, followed by 40 cycles at $94^{\circ} \mathrm{C}$ for $15 \mathrm{~s}, 60^{\circ} \mathrm{C}$ for $30 \mathrm{~s}$ and $72^{\circ} \mathrm{C}$ for $30 \mathrm{~s}$. Experiments were performed in duplicate.

Expression of five housekeeping genes (ACTB, TFRC, GUSB, PPIA, and RPLP0) was first tested in 15 breast cancer samples (11) and expression of ACTB and RPLP0 was the most stable among samples. ACTB was then chosen as a reference gene. Relative expression of genes of interest was normalized to that of HB4A cells (normal mammary epithelial lineage). Investigated transcripts showed high real-time PCR efficiency rates (around 1.0) and relative expression was calculated as $2^{-\Delta \Delta C T}$. Results were then transformed to their natural logarithm values.

\section{Detection of circulating epithelial cells using nested RT-PCR}

Epithelial cells recovered from peripheral blood MNCs after immunoselection with Dynabeads had their mRNA extracted and processed by nested PCR to evaluate the expression of cytokeratin 19 (KRT19), a protein expressed by epithelial cells. The first reaction took place in the presence of $1 \mu \mathrm{L}$ cDNA, Taq recombinant DNA Polymerase (Invitrogen) and external primers (Table 3). Amplification conditions consisted of $95^{\circ} \mathrm{C}$ for $2 \mathrm{~min}$, followed by 35 cycles at $95^{\circ} \mathrm{C}$ for $15 \mathrm{~s}, 62^{\circ} \mathrm{C}$ for $1 \mathrm{~min}$, and $72^{\circ} \mathrm{C}$ for $1 \mathrm{~min}$. The second PCR was performed using $1 \mu \mathrm{L}$ of the product of the first reaction and a second pair of internal primers (Table 3 ), under the same conditions as described above, for 25 amplification cycles. The product was detected under UV light as a band of 461 bp on $2 \%$ agarose gel containing ethidium bromide.

To establish the ideal number of amplification cycles, a serial dilution of HB4A cells (2, 5 and 10 cells) with promyelocytic leukemia HL60 cells $\left(1 \times 10^{6}\right)$ was performed. The first round of PCR revealed no product. The second PCR, performed using a variable number of cycles, revealed a characteristic product after 25 cycles for all dilutions of HB4A cells in HL60 cells (Figure 1A).

\section{Immunohistochemistry}

Sections (3- $\mu \mathrm{m}$ thick) were cut from paraffin blocks containing invasive cancer, and immunohistochemistry reactions were carried out to detect E-cadherin (mouse monoclonal IgG1 anti-human antibody, clone $\mathrm{NCH}-38$, DAKO M3612, dilution 1:100) (DAKO Corporation, USA) or SNAI1 [(E-18): sc-10432 goat polyclonal IgG anti-human SNAI1 internal region; Santa Cruz Biotechnology, Inc., USA, dilution 1:50] with antigen retrieval performed by pressure cooking in 10-mM citrate buffer at $\mathrm{pH} 6.0$ for 4 min. Detection was done using the StreptAB Complex/ HRP duet (Dako k492, 1:200) or horseradish peroxidase anti-goat IgG conjugate (Vector Labs, USA) and DAB (Sigma D5637; Sigma-Aldrich Corp., USA).

E-cadherin staining was evaluated as negative, if absent or low (no immunostaining or immunopositivity $\leq 10 \%$ or low-intensity partial membrane staining in $>10 \%$ of cells) or positive (low, moderate or intense complete membrane staining in $>10 \%$ of cells). The entire tumor represented in the section was assessed. Appropriate positive and negative controls were run with each batch (lobular and ductal invasive carcinomas).

Snail expression was evaluated as negative (nil or $\leq 10 \%$ of cells) or positive ( $>10 \%$ of cells). Negative controls were obtained by the omission of the primary antibody. Immunostaining for Snail was mainly observed in the cytoplasm and only two patients presented nuclear staining.

\section{Statistical analysis}

The Kolmogorov-Smirnov test of normality was applied to verify the distribution pattern of expression values. A normal distribution was detected for expression values of matched tumor/peritumor samples and therefore parametric tests (paired $t$-test and Pearson correlation) were used. When normal distribution was not detected, non-parametric tests (Mann-Whitney for independent variables, and Spearman correlation) were used. The level of significance was set at $\leq 0.05$ in all analyses. Association between variables was determined using the Fisher exact test. The SPSS statistical software version 11.0 (USA) was used.

Table 3. Primer sequences used in RT-PCR.

\begin{tabular}{lcccc}
\hline Gene & Genbank accession number & Primer sense (5'-3') & Primer antisense (5'-3') & Product size (bp) \\
\hline CK19 & NM_002276 & CACTACTACACGACCATCCAGGAC & CAAATTGTTGTAGTGATCTTCCTG & 798 \\
CK19 & NM_002276 & TTTGAGACGGAACAGGCTCT & TCTTCCAAGGCAGCTTTCAT & 461 \\
CDH1 & NM_004360 & CTTGGTCTACGCCTGGGACT & TGTGAGCAATTCTGCTTGGA & 150 \\
SNAl1 & NM_00598 & TGGGTGAATTCGGGCTTG & CAAGATGCACATCCGAAGC & 134 \\
HAKAI & NM_024814 & TCACTGCACAGGATCACTAC & TAAAGGGGGTGAGCTGTTTG & 243 \\
ACTB & NM_001101 & AGAAAATCTGGCACCAACC & AGAGGCGTACAGGGATAGCA & 188 \\
\hline
\end{tabular}




\section{Results}

A paired analysis of the expression of E-cadherin (CDH1), Snail (SNAI1) and Hakai transcripts between the selected epithelial malignant component of tumors and its adjacent normal tissue was performed. Our data indicate that the expression levels of these target genes are widely distributed (Figure 2), irrespective of the tissue origin (tumor or normal).

CDH1 mRNA expression was evaluated in 22 paired samples and a positive correlation was detected between them $(r=0.697 ; P<0.01$; Pearson correlation); however, no differential expression between the primary tumor $(0.12$ \pm 2.51 ) and corresponding peritumoral tissue $(-0.34 \pm 2.45)$ was observed (Figure 2). SNAI1 mRNA expression was evaluated in 25 paired samples and neither differential expression (primary tumor $=3.59 \pm 2.31$ vs peritumoral tissue $=3.59 \pm 2.31$ ) nor correlation between pairs was detected. Hakai mRNA expression was determined in 22 paired samples and no correlation was observed. Although there was no significant differential expression of HAKAI between matched samples (primary tumor $=2.30 \pm 2.47$ vs peritumoral tissue $=1.28 \pm 2.67$ ), 12 tumor specimens showed a higher expression (samples 4, 5, 11, 12, 15, 16 , $18,21,22,24,28,29)$ compared to the corresponding peritumoral samples (Figure 2).

A positive correlation was detected between tumoral expression of E-cadherin and Snail $(\mathrm{N}=18, \mathrm{r}=0.564, \mathrm{P}$ $=0.015$, Spearman correlation) and Snail and Hakai $(\mathrm{N}=$ $19, r=0.611, P=0.005$, Spearman correlation). A trend towards a positive correlation between E-cadherin and Hakai expression was also observed $(N=15, r=0.454, P$ $=0.089$, Spearman correlation).

mRNA expression of all three target genes was analyzed in 13 matched samples (tumor and peritumoral) and discriminant analysis was performed using these variables. However, only $65.4 \%$ of the originally grouped cases would be correctly classified (Figure 3), indicating that these parameters could not be used for this purpose.

We then evaluated whether there were differences in tumor gene expression between patients with involved nodes and patients with uninvolved nodes. However, we observed no differences in E-cadherin, Snail or Hakai mRNA tumor expression according to the presence of regional metastases (Figure 4A).

We also determined whether E-cadherin, Snail and

A
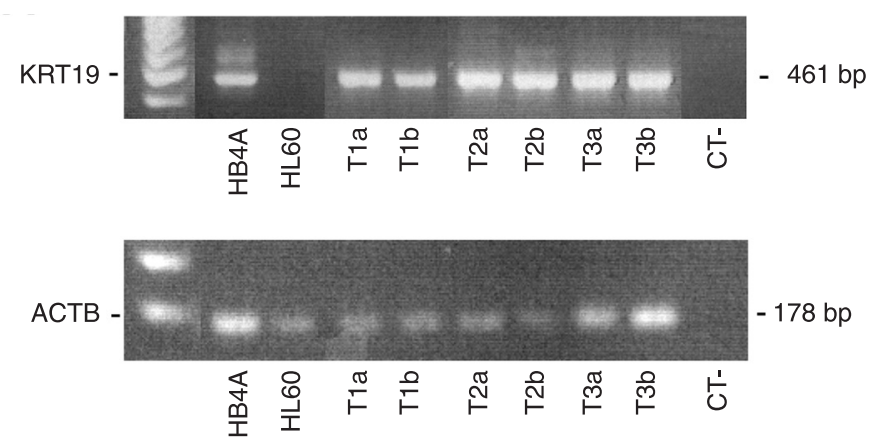

B
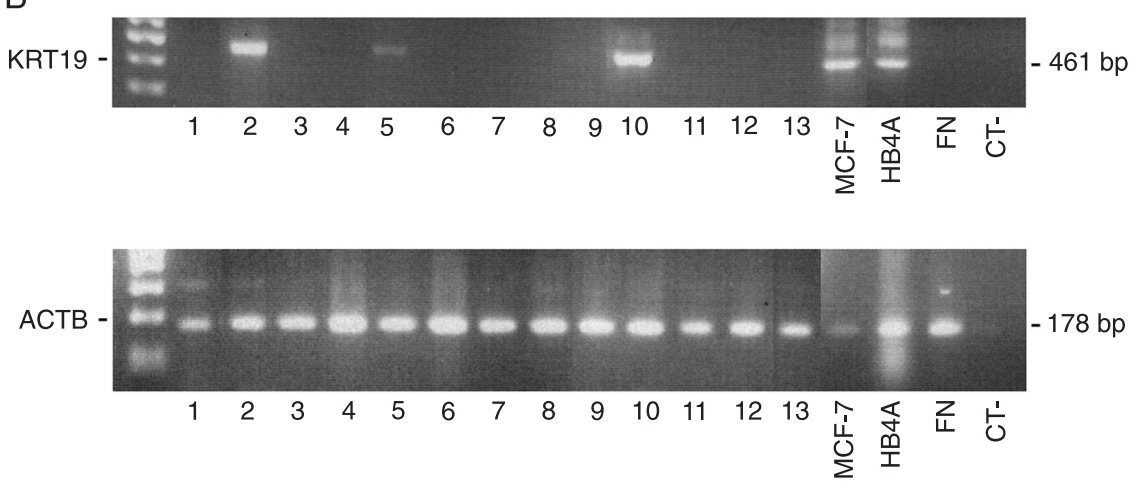

Figure 1. KRT19 detection by nested RT-PCR. A, HB4A cells [T1 ( $\mathrm{N}=2$ cells); T2 ( $\mathrm{N}=5$ cells); T3 ( $\mathrm{N}=10$ cells] were diluted in $10^{6}$ HL60 cells. Experiments were performed in duplicate ( $\mathrm{a}$ and b). Epithelial cells were recovered with Dynabeads and, after nested PCR, bands of 461 and $178 \mathrm{bp}$ corresponding to KRT19 and ACTB were visible. HB4A and HL60 cells were used as positive and negative controls, respectively. B, Circulating tumor cells (CT) as detected by KRT19 expression by nested RT-PCR in mononuclear cells obtained from the peripheral blood of breast cancer patients. Bands of 461 and 178 bp corresponding to KRT19 and ACTB may be seen in samples from three patients. MCF7 and/ or HB4A cells were used as positive control and a pool of lymphocytes obtained from three healthy individuals (FN), as negative controls. 

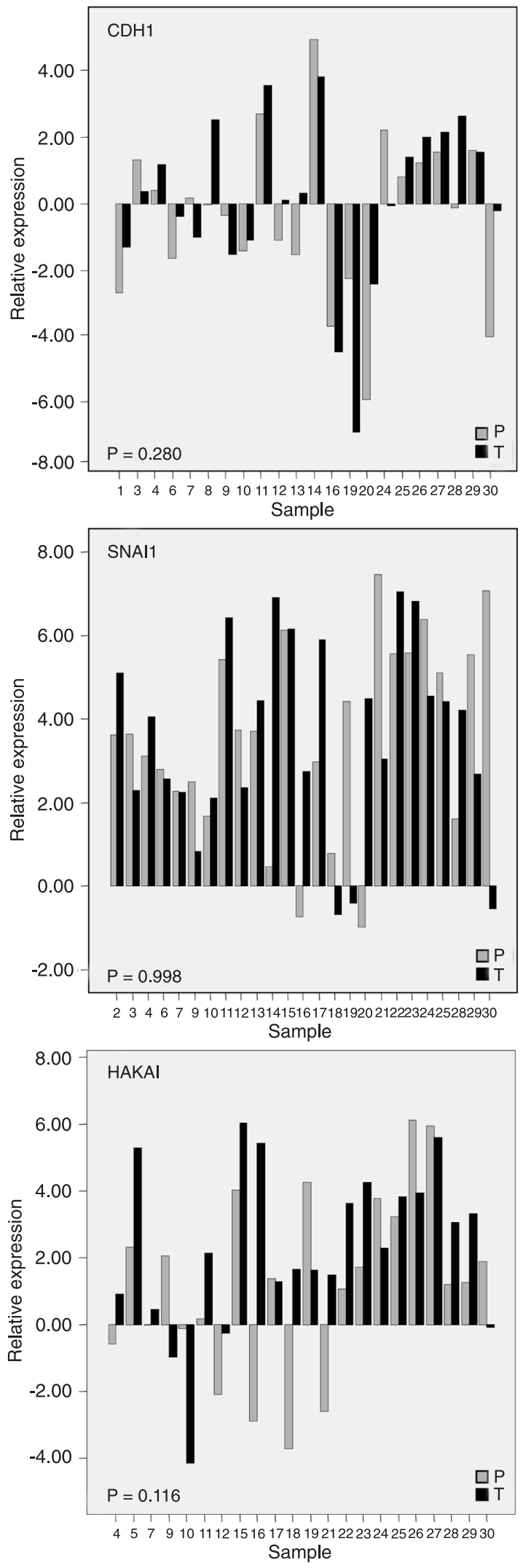

Figure 2. CDH1, SNAI1, and HAKAI mRNA expression in epithelial cells isolated from the primary tumor site and its normal adjacent tissue. Epithelial cells from tumor $(T)$ and peritumoral $(P)$ sites were recovered separately by immunomagnetic positive selection. Relative expression was calculated as described in Methods and is shown on the $y$-axis as its natural logarithm ( $L n)$ value. Individual expression values are shown and sample identification appears on the $\mathrm{x}$-axis. Not all 30 specimens had the expression values for the three target genes evaluated in paired samples. Since data followed a normal distribution, the paired $t$-test was employed and $\mathrm{P}$ values appear inside the figures. 


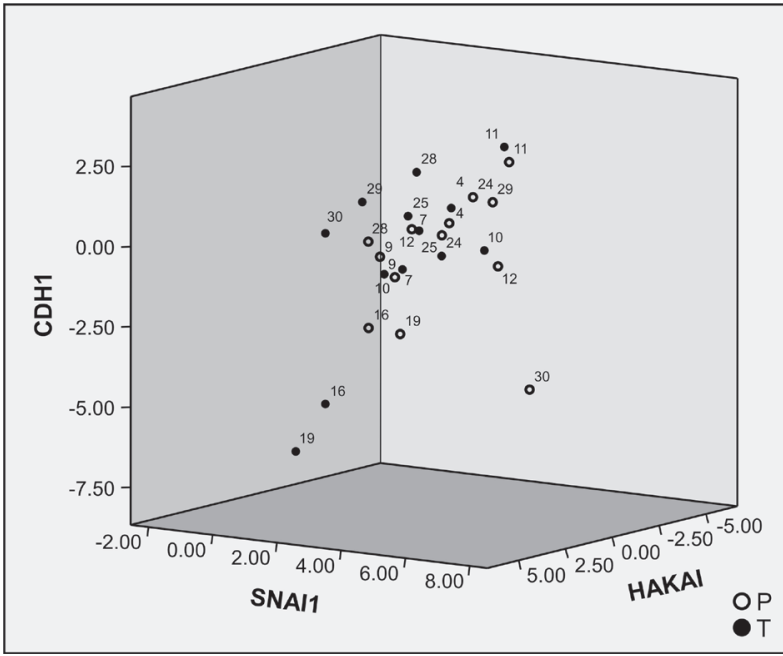

Figure 3. Three-dimensional distribution of tumor $(T)$ and peritumoral $(P)$ samples according to CDH1, SNAI1 and HAKAI mRNA expression. Thirteen patients had all three target genes evaluated in matched samples. Discriminant analysis classified $65.4 \%$ of the samples in the correct group.
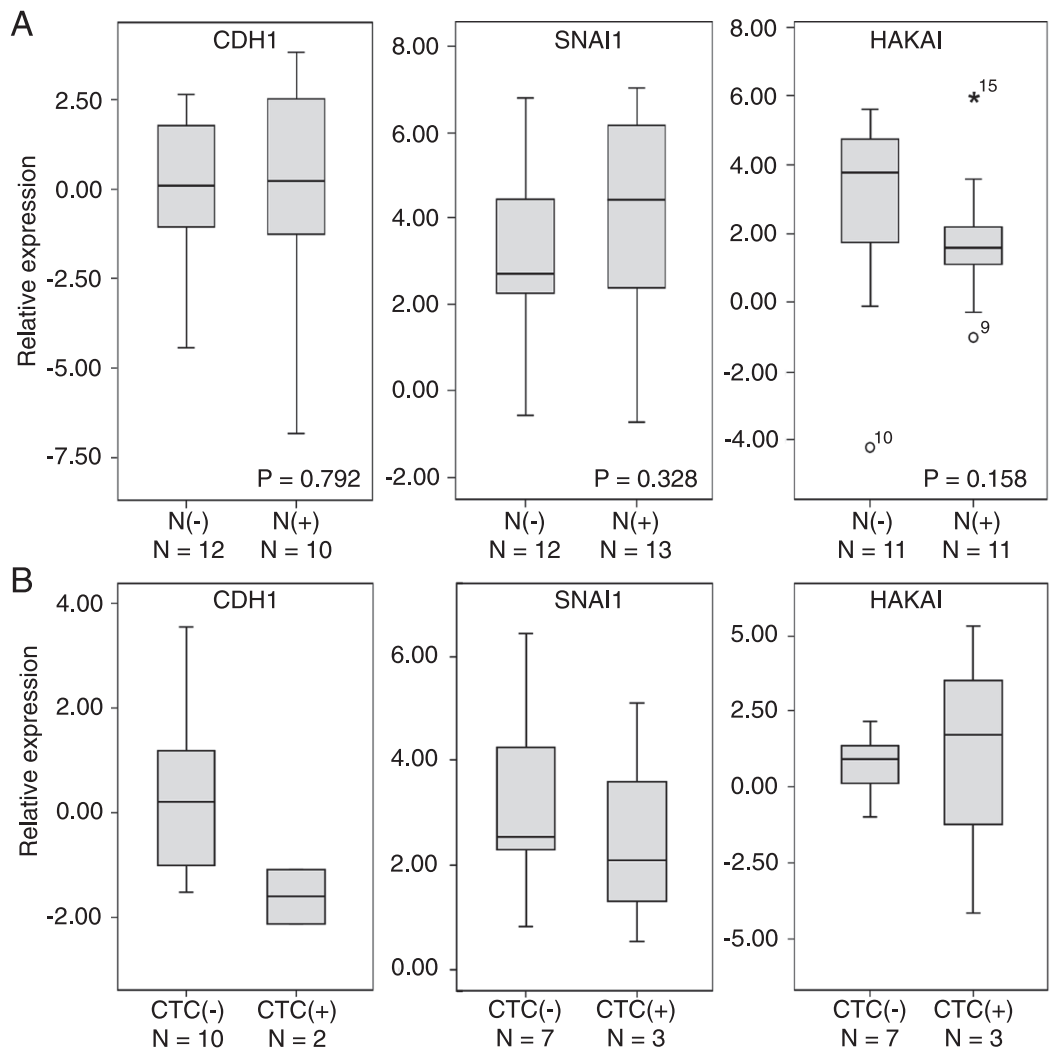

Figure 4. $A, \mathrm{CDH} 1, \mathrm{SNAI} 1$, and HAKAI mRNA expression in tumor specimens according to the presence $[\mathrm{N}(+)]$ or absence of lymph node involvement [N(-)]. Boxplots display the distribution of all values between bars (25th, 50th and 75th percentiles in the box), except outliers (circles, 1.5-3.0 box lengths from the 75th quartile; asterisks, >3.0 box lengths from the 75th percentile). No differences were observed (Mann-Whitney test). B, CDH1, SNAI1, and HAKAI mRNA expression in tumor specimens according to the presence of circulating tumor cells (CTC) [presence $(+)$ or absence $(-)$ ]. 


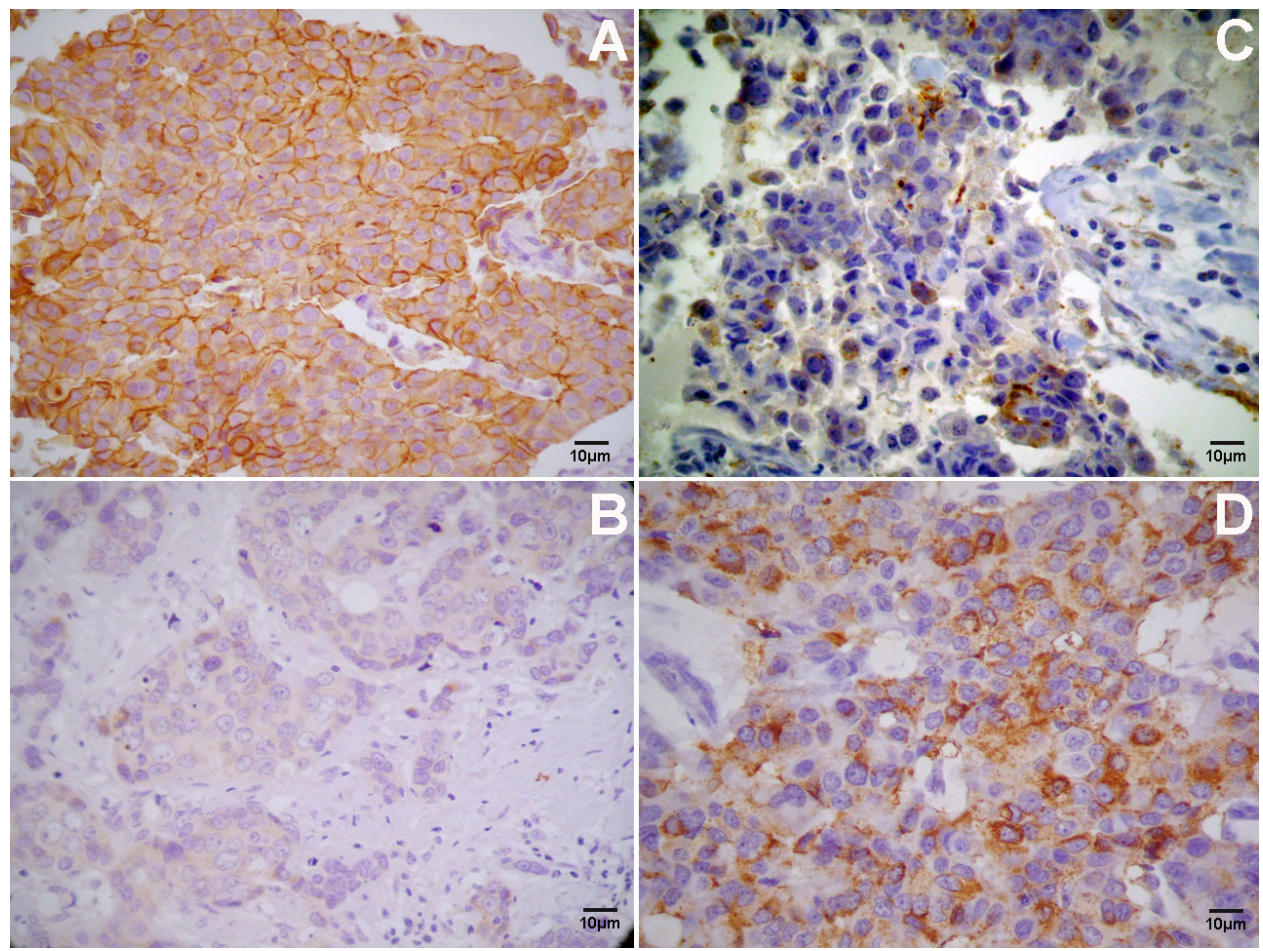

Figure 5. E-cadherin and Snail immunoexpression in breast cancer specimens. $A$ and $C$, E-cadherin membranous-positive expression in tumor cells and Snail-negative expression in a specimen from a patient from the good prognosis group (Pt 5). B, Negative immunostaining for E-cadherin in a tumor sample from a patient assigned to the poor prognosis group ( $\mathrm{Pt} 24)$. $D$, Snail-positive tumor immunoexpression in a patient ( $\mathrm{Pt}$ 9) from the good prognosis group. Snail immunoexpression was mainly observed in the cytoplasm (40X).

Table 4. E-cadherin and Snail immunoexpression in breast cancer specimens from patients assigned to the good and poor prognosis groups.

\begin{tabular}{lcc}
\hline & Good prognosis & Poor prognosis \\
\hline E-cadherin(-) & 2 & 4 \\
E-cadherin(+) & $19^{*}$ & 5 \\
Snail(-) & 8 & 6 \\
Snail(+) & 13 & 3 \\
\hline
\end{tabular}

${ }^{*} \mathrm{P}<0.05$ E-cadherin expression in good $v s$ poor prognosis groups (Fisher exact test).

Hakai mRNA tumor expression was associated with the presence of circulating malignant cells, as determined by KRT19 expression in blood MNCs (Figure 1B). Circulating tumor cells were detected in blood samples from three of 13 patients. Boxplots (Figure 4B) suggest that there was a trend towards a lower E-cadherin mRNA expression (but not Snail or Hakai) in tumor samples from these patients with circulating tumor cells.

In addition, we determined whether E-cadherin and Snail immunoexpression could be associated with breast cancer distant metastases and death in another group of patients with a minimum follow-up of five years (Figure 5). Negative E-cadherin expression was observed in 6 samples, 4 of them belonging to the poor prognosis group (Table 4) and inversely, positive E-cadherin expression was observed in 24 tumor specimens, 19 of them from the good prognosis group. These data indicate an association between E-cadherin protein negativity and poor prognosis and, conversely, between positivity and good prognosis (Table 4). Positive Snail expression was observed in 16 samples but no association with the prognosis group was detected (Table 4).

\section{Discussion}

Our assumption was that invasive ductal carcinomas might present changes in E-cadherin, Snail or Hakai mRNA expression as compared to their paired normal adjacent tissue; however, no differential expression was observed. Our data indicate that invasive carcinomas and their normal adjacent tissue share the same characteristics concerning the mRNA expression of these genes, i.e., if expression is low in the tumor, it is also low in the normal adjacent tissue and vice-versa. One limitation of our study was the small sample size, its strength was that the epithelial compo- 
nent was individually analyzed using a sensitive method, which may allow measurements of expression levels as a continuous variable. In addition, three target genes, Ecadherin, Snail and Hakai, were concomitantly analyzed in the matched samples. Another study, carried out on a larger sample of matched tumor and metastasis specimens from ductal carcinomas, did not detect differences in E-cadherin protein staining intensity (9). Taken together, these results and ours suggest that, in general, ductal carcinomas, represented by the primary tumor, its peritumoral tissue and its nodal metastases, maintain their E-cadherin expression throughout their development, including invasiveness and establishment in other tissues. On the other hand, a reduction of E-cadherin protein expression was reported in a small series of invasive ductal carcinomas as compared to ductal carcinomas in situ (12). Differences between this analysis and ours were that samples were obtained from different patients and were not paired in the previous study. It was also reported that reduction or lack of E-cadherin protein expression in non-lobular breast cancer is preferentially found in basal-like carcinomas (13). However, our samples were mainly represented by hormone receptorpositive tumors. Another consideration is that both studies analyzed E-cadherin protein expression, which is also regulated post-transcriptionally. In our study, Hakai mRNA was more expressed in 12/22 tumors compared to their matched peritumor samples, suggesting that E-cadherin degradation mediated by Hakai may be up-regulated at least in a few tumors. In addition, other mechanisms may be involved in E-cadherin down-regulation at the protein level $(14,15)$ that may occur through endocytosis $(16,17)$, and these were not investigated here.

A positive correlation between Snail and E-cadherin mRNA expression in invasive ductal carcinoma samples has been reported (18), as also observed in the present study. In addition, although in vitro studies using cell lines have indicated that induced overexpression of Snail in mammary normal or transformed cell lines represses Ecadherin transcription, the same does not seem to occur in tumor samples (18). Hence, observations in breast tumor samples underscore the role of other regulatory elements in addition to Snail in physiologic E-cadherin transcription regulation.

We also evaluated whether tumor expression of E-cadherin, Snail and Hakai mRNA could be related to regional metastasis since the presence of involved lymph nodes suggests that tumor spreading may have occurred

\section{References}

1. Kang Y, Massague J. Epithelial-mesenchymal transitions: twist in development and metastasis. Cell 2004; 118: 277279.

2. Yang J, Weinberg RA. Epithelial-mesenchymal transition: at through the lymphatics. However, we could not find any association. In agreement, no relation between lymph node involvement and E-cadherin immunohistochemical expression was detected by others in non-lobular carcinomas $(8,19)$. Conversely, Snail overexpression in tumors from patients with node $(18,20)$ and distant metastases $(21)$ has also been reported.

Circulating tumor cells were detected in three of the 13 patients tested, in agreement with results previously reported in clinical stage I-III breast cancer disease $(22,23)$. Although we studied a small number of samples, we may speculate that there may be a trend towards a low E-cadherin expression in tumor samples from patients with circulating malignant cells that could facilitate tumor shedding through the vascular channels. Other investigators have not found a relation between blood vessel invasion and E-cadherin expression (24). However, their sample also included lobular and other carcinoma samples and not just ductal carcinomas.

Complete absence of E-cadherin protein immunoexpression was observed in $10 \%$ of the tumors analyzed here, in agreement with data reported by others $(8,13,25,26)$. In addition, positive E-cadherin expression was associated with a better prognosis, in agreement with a previous report (19).

We detected Snail protein nuclear localization in just two of the 30 samples analyzed. Similarly, Rosivatz et al. (26), studying a large series of adenocarcinomas of the upper gastrointestinal tract, observed nuclear Snail immunoreactivity in only $7.9 \%$ of them. We speculate that Snail may not be exerting its function as a transcriptional factor in ductal carcinomas.

This is the first report to analyze the concomitant expression of CDH1, SNAI1 and Hakai mRNA in matched tumor and peritumoral samples from patients with invasive ductal carcinomas. Our data suggest that there is no clear pattern of expression of these target genes that may classify the tumor specimen and its adjacent normal tissue. Our study also indicates that tumor E-cadherin protein expression may be related to overall breast cancer survival.

\section{Acknowledgments}

The authors would like to acknowledge the helpful assistance of Mrs. Cintia Milani with nested PCR, and Mrs. Maria José Gonçalves Benevides for secretarial help. Research supported by FAPESP and CAPES. 
tion in tumor cells is accompanied by MUC1 repression and ZEB1 expression. J Biol Chem 2002; 277: 39209-39216.

4. Bolos V, Peinado H, Perez-Moreno MA, Fraga MF, Esteller M, Cano A. The transcription factor Slug represses E-cadherin expression and induces epithelial to mesenchymal transitions: a comparison with Snail and E47 repressors. $J$ Cell Sci 2003; 116: 499-511.

5. Cano A, Perez-Moreno MA, Rodrigo I, Locascio A, Blanco MJ, del Barrio MG, et al. The transcription factor snail controls epithelial-mesenchymal transitions by repressing E-cadherin expression. Nat Cell Biol 2000; 2: 76-83.

6. Fujita Y, Krause G, Scheffner M, Zechner D, Leddy HE, Behrens J, et al. Hakai, a c-Cbl-like protein, ubiquitinates and induces endocytosis of the E-cadherin complex. Nat Cell Biol 2002; 4: 222-231.

7. Acs G, Lawton TJ, Rebbeck TR, LiVolsi VA, Zhang PJ. Differential expression of E-cadherin in lobular and ductal neoplasms of the breast and its biologic and diagnostic implications. Am J Clin Pathol 2001; 115: 85-98.

8. Rakha EA, Abd El Rehim D, Pinder SE, Lewis SA, Ellis IO. $\mathrm{E}$-cadherin expression in invasive non-lobular carcinoma of the breast and its prognostic significance. Histopathology 2005; 46: 685-693.

9. Harigopal M, Berger AJ, Camp RL, Rimm DL, Kluger HM. Automated quantitative analysis of $\mathrm{E}$-cadherin expression in lymph node metastases is predictive of survival in invasive ductal breast cancer. Clin Cancer Res 2005; 11: 40834089.

10. Kist D, Perkins W, Christ S, Zachary CB. Anti-human epithelial antigen (Ber-EP4) helps define basal cell carcinoma masked by inflammation. Dermatol Surg 1997; 23: 10671070.

11. Vandesompele J, De Preter K, Pattyn F, Poppe B, Van Roy N, De Paepe A, et al. Accurate normalization of realtime quantitative RT-PCR data by geometric averaging of multiple internal control genes. Genome Biol 2002; 3: RESEARCH0034.

12. Jeschke U, Mylonas I, Kuhn C, Shabani N, Kunert-Keil C, Schindlbeck C, et al. Expression of E-cadherin in human ductal breast cancer carcinoma in situ, invasive carcinomas, their lymph node metastases, their distant metastases, carcinomas with recurrence and in recurrence. Anticancer Res 2007; 27: 1969-1974.

13. Mahler-Araujo B, Savage K, Parry S, Reis-Filho JS. Reduction of E-cadherin expression is associated with non-lobular breast carcinomas of basal-like and triple negative phenotype. J Clin Pathol 2008; 61: 615-620.

14. Xue Y, Wang X, Li Z, Gotoh N, Chapman D, Skolnik EY. Mesodermal patterning defect in mice lacking the Ste20 NCK interacting kinase (NIK). Development 2001; 128 : 1559-1572.
15. Zohn IE, Li Y, Skolnik EY, Anderson KV, Han J, Niswander L. p38 and a p38-interacting protein are critical for downregulation of E-cadherin during mouse gastrulation. Cell 2006; 125 : 957-969.

16. Ogata S, Morokuma J, Hayata T, Kolle G, Niehrs C, Ueno N, et al. TGF-beta signaling-mediated morphogenesis: modulation of cell adhesion via cadherin endocytosis. Genes Dev 2007; 21: 1817-1831.

17. Hirano M, Hashimoto S, Yonemura S, Sabe H, Aizawa S. EPB41L5 functions to post-transcriptionally regulate cadherin and integrin during epithelial-mesenchymal transition. J Cell Biol 2008; 182: 1217-1230.

18. Come C, Magnino F, Bibeau F, De Santa Barbara P, Becker $\mathrm{KF}$, Theillet C, et al. Snail and slug play distinct roles during breast carcinoma progression. Clin Cancer Res 2006; 12: 5395-5402.

19. Park D, Karesen R, Axcrona U, Noren T, Sauer T. Expression pattern of adhesion molecules (E-cadherin, alpha-, beta-, gamma-catenin and claudin-7), their influence on survival in primary breast carcinoma, and their corresponding axillary lymph node metastasis. APMIS 2007; 115: 52-65.

20. Blanco MJ, Moreno-Bueno G, Sarrio D, Locascio A, Cano A, Palacios J, et al. Correlation of Snail expression with histological grade and lymph node status in breast carcinomas. Oncogene 2002; 21: 3241-3246.

21. Toyama T, Zhang Z, Iwase H, Yamashita H, Ando Y, Hamaguchi $\mathrm{M}$, et al. Low expression of the snail gene is a good prognostic factor in node-negative invasive ductal carcinomas. Jpn J Clin Oncol 2006; 36: 357-363.

22. Stathopoulou A, Vlachonikolis I, Mavroudis D, Perraki M, Kouroussis C, Apostolaki S, et al. Molecular detection of cytokeratin-19-positive cells in the peripheral blood of patients with operable breast cancer: evaluation of their prognostic significance. J Clin Oncol 2002; 20: 3404-3412.

23. Hayes DF, Smerage J. Is there a role for circulating tumor cells in the management of breast cancer? Clin Cancer Res 2008; 14: 3646-3650.

24. Marinho VF, Metze K, Sanches FS, Rocha GF, Gobbi H. Lymph vascular invasion in invasive mammary carcinomas identified by the endothelial lymphatic marker D2-40 is associated with other indicators of poor prognosis. BMC Cancer 2008; 8: 64.

25. Caldeira JR, Prando EC, Quevedo FC, Neto FA, Rainho CA, Rogatto SR. CDH1 promoter hypermethylation and $\mathrm{E}$-cadherin protein expression in infiltrating breast cancer. BMC Cancer 2006; 6: 48.

26. Rosivatz E, Becker KF, Kremmer E, Schott C, Blechschmidt $\mathrm{K}$, Hofler $\mathrm{H}$, et al. Expression and nuclear localization of Snail, an E-cadherin repressor, in adenocarcinomas of the upper gastrointestinal tract. Virchows Arch 2006; 448: 277287. 